Article

\title{
Anionic Polymer Brushes for Biomimetic Calcium Phosphate Mineralization-A Surface with Application Potential in Biomaterials
}

\author{
Tobias Mai ${ }^{1}$, Karol Wolski ${ }^{2}{ }^{-}$, Agnieszka Puciul-Malinowska ${ }^{2}$, Alexey Kopyshev ${ }^{3}$, \\ Ralph Gräf ${ }^{4}$, Michael Bruns ${ }^{5}\left[\right.$, Szczepan Zapotoczny ${ }^{2, *}{ }^{\circledR}$ and Andreas Taubert ${ }^{1, *}$ \\ 1 Institute of Chemistry, University of Potsdam, D-14476 Potsdam, Germany; mai.tobias@gmx.net \\ 2 Faculty of Chemistry, Jagiellonian University, Gronostajowa 2, 30-387 Krakow, Poland; \\ wolski@chemia.uj.edu.pl (K.W.); puciul@chemia.uj.edu.pl (A.P.-M.) \\ 3 Institute of Physics and Astronomy, University of Potsdam, D-14476 Potsdam, Germany; \\ kopyshev@uni-potsdam.de \\ 4 Institute of Biochemistry and Biology, University of Potsdam, D-14476 Potsdam, Germany; \\ rgraef@uni-potsdam.de \\ 5 Institute for Applied Materials and Karlsruhe Nano Micro Facility (KNMF), Karlsruhe Institute of \\ Technology, D-76344 Eggenstein-Leopoldshafen, Germany; michael.bruns@kit.edu \\ * Correspondence: zapotocz@chemia.uj.edu.pl (S.Z.); ataubert@uni-potsdam.de (A.T.); \\ Tel.: +48-12-686-2530 (S.Z.); +49-331-977-5773 (A.T.)
}

Received: 28 August 2018; Accepted: 7 October 2018; Published: 18 October 2018

\begin{abstract}
This article describes the synthesis of anionic polymer brushes and their mineralization with calcium phosphate. The brushes are based on poly(3-sulfopropyl methacrylate potassium salt) providing a highly charged polymer brush surface. Homogeneous brushes with reproducible thicknesses are obtained via surface-initiated atom transfer radical polymerization. Mineralization with doubly concentrated simulated body fluid yields polymer/inorganic hybrid films containing AB-Type carbonated hydroxyapatite (CHAP), a material resembling the inorganic component of bone. Moreover, growth experiments using Dictyostelium discoideum amoebae demonstrate that the mineral-free and the mineral-containing polymer brushes have a good biocompatibility suggesting their use as biocompatible surfaces in implantology or related fields.
\end{abstract}

Keywords: polymer brushes; calcium phosphate; hydroxyapatite; carbonated apatite; bone mimic; biocompatibility; Dictyostelium discoideum

\section{Introduction}

The expected lifetime at birth has dramatically increased over the last 150 years. For example, life expectancy in Germany has more than doubled-from 37 years in 1871 to about 80 years in 2010 [1]. Among others, this is due to improved nutrition supplies and society-induced changes to physical activity patterns. However, as a consequence of this lifetime extension, diseases that were virtually unknown 200 years ago have become major factors in today's health industries. These diseases include osteoporosis, chondrocalcinosis, kidney stones, atherosclerosis, but also caries and calculus.

Many of the diseases mentioned above are associated with the (unwanted or uncontrolled) deposition or dissolution of, mostly calcium-based, mineral deposits in the body. Biological mineral deposition is a highly complex physico-chemical process that is among the key processes to control in biomaterials design. Often, (biological) mineral formation and dissolution occur at an interface. This has triggered a number of studies on the effects of surfaces and interfaces on mineral deposition, notably calcium phosphate $(\mathrm{CP})[2-8]$. 
Understanding and controlling surface- and interface-controlled mineral formation may also be helpful for improving the design of biomaterial surfaces, because initially, the incorporation of an implant is again controlled by the interaction of the implant surface with the body. As a result, there is a need for tailor-made (model) surfaces that enable (i) the investigation of mineral formation and dissolution; (ii) the behavior of these surfaces in vitro and (iii) in vivo. Polymer brushes are one strategy for investigating these phenomena and processes [9-14].

The current work focuses on negatively charged polymer brushes grafted on silicon wafers as a model surface. The 3-sulfopropyl methacrylate (SPM) chemistry employed here is inspired by the fact that block copolymers of poly(ethylene oxide) (PEO) and poly(3-sulfopropyl methacrylate) (PSPM) exhibit very strong effects on CP mineralization [15]. Importantly, PSPM chains are highly negatively charged over a much broader $\mathrm{pH}$ range than previous examples of polymer surfaces [5]. Indeed, several studies $[10,12,16]$ show that surfaces carrying a large number of sulfonate groups lead to metal ion enrichment and subsequent precipitation of a variety of minerals.

Somewhat surprisingly, however, there is only one study on CP mineralization demonstrating favorable effects for calcium phosphate mineralization both with negatively and positively charged weak polyelectrolyte surfaces [5]. The current study demonstrates that strong polyelectrolyte brushes may be even more attractive for the generation of hybrid thin layers than the brushes studied so far because they are highly charged from ca. $\mathrm{pH} 2$ up; this makes them very interesting for the generation of surfaces that remain charged under physiological conditions, for example on an implant surface. The surfaces described here are thus much better models (and potential surface modifiers for implants) than our previous examples [5] for the investigation of bioinspired surface mineralization.

\section{Materials and Methods}

Sulfuric acid ( $98 \%$ for analysis), aqueous hydrogen peroxide (30\% for synthesis), benzene (ACS, ISO, Reag. Ph. Eur. for analysis), dichloromethane (DCM; ACS, ISO, Reag. Ph. Eur. for analysis), ethanol ( $>96 \%$ not denaturized), and chloroform (ACS, ISO, Reag. Ph. Eur. for analysis) were purchased from VWR international ${ }^{\circledR}$ (Darmstadt, Germany) and 3-iodopropyltrimethoxysilane, 3-aminopropyltrimethoxysilane $(97 \%)$ and ( $N$-methylaminopropyl)trimethoxysilane from abcr ${ }^{\circledR}$ (Karlsruhe, Germany). Poly(ethylene oxide) (PEO4600, nominal $\left.\mathrm{M}_{\mathrm{W}}=4600 \mathrm{~g} / \mathrm{mol}\right), N, N, N^{\prime}, N^{\prime}$-tetramethylethylenediamine (TMEDA) (ReagentPlus ${ }^{\circledR}$, $99 \%$, freshly distilled), 3-sulfopropylmethacrylate potassium salt (SPM) $(98 \%)$, triethylamine ( $\geq 99 \%)$ and $2 \mathrm{M}$ lithium diisopropylamine (LDA) in tetrahydrofurane (THF), $N$-propyl gallate and $\alpha$-bromoisobutyryl bromide $(98 \%)$ were purchased from Sigma Aldrich ${ }^{\circledR}$ (Taufkirchen, Germany). HL5c medium was obtained from Formedium (Hunsanton, UK), 24 well cell culture plates from Sarstedt (Nümbrecht, Germany), glutaraldehyde ( $0.5 \%)$ from Plano (Wetzlar, Germany), and the silicon wafer with diameter of $150 \mathrm{~mm}$ and $<100>$ orientation from SI-MAT (Kaufering, Germany). All chemicals were used as received.

Ultrapure water with a resistivity of $18.2 \mathrm{M} \Omega \cdot \mathrm{cm}$ was obtained fresh from an ELGA Pure Lab ultra machine (Celle, Germany). Dry solvents were prepared according to previously published procedures [17].

\subsection{Preparation}

Prior to further use, wafer sections of $\sim 1 \times 1 \mathrm{~cm}^{2}$ were generously rinsed with ethanol, chloroform, ethanol, and ultrapure water. After drying with an Ar-stream the wafers were treated with fresh piranha solution (1:1 $(v / v)$ sulfuric acid/aqueous hydrogen peroxide) for $30 \mathrm{~s}$, again generously rinsed with ultrapure water and finally dried with argon.

\subsection{Sample Nomenclature}

The sample numbers are kept the same throughout the text: for example, the precursor Prec1 is transformed into the initiator Ini1 which is then transformed into the polymer brush Brush1 and finally into the mineralized sample Min1 (Figure 1). The same applies to the other samples. 

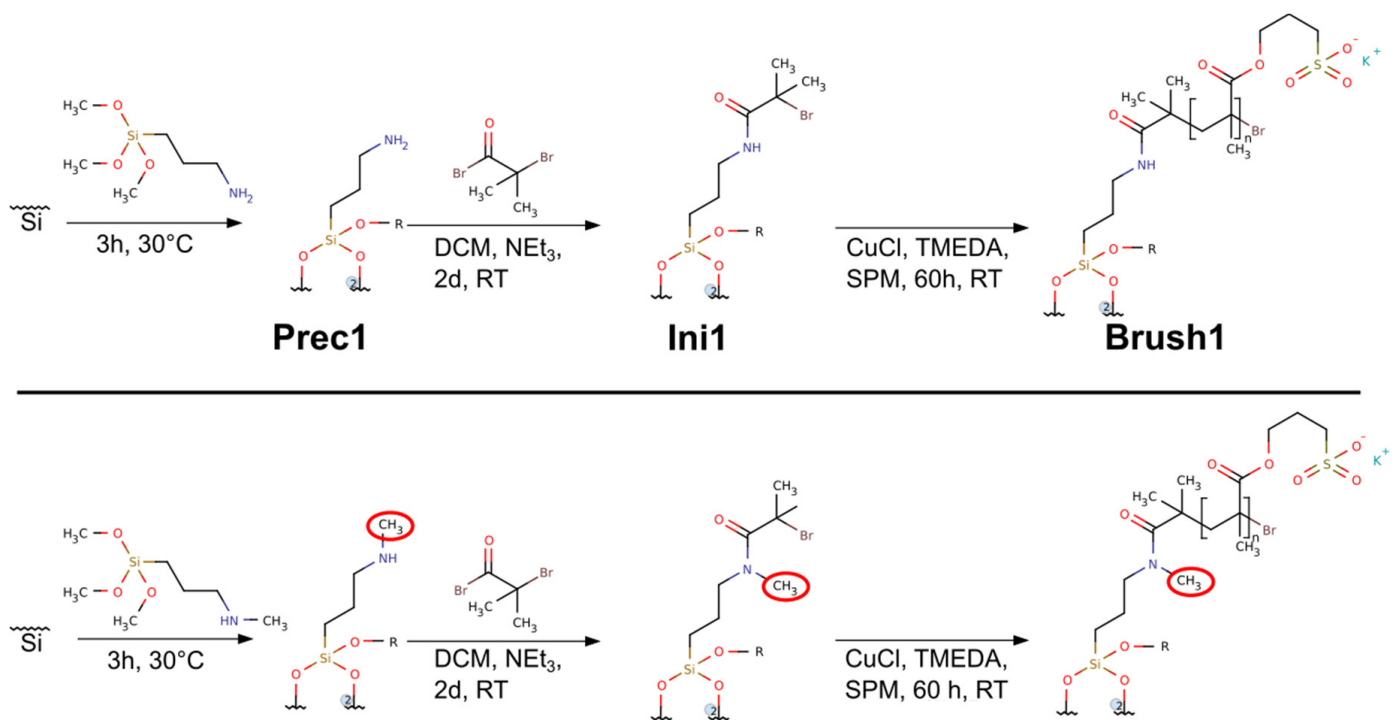

Prec2

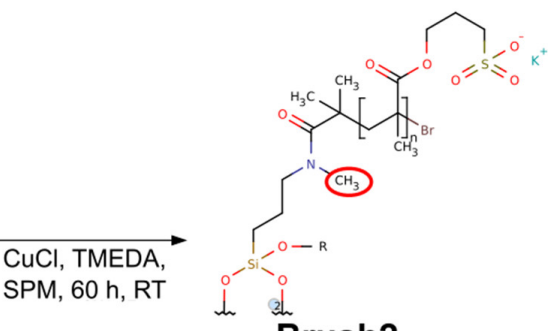

Brush2
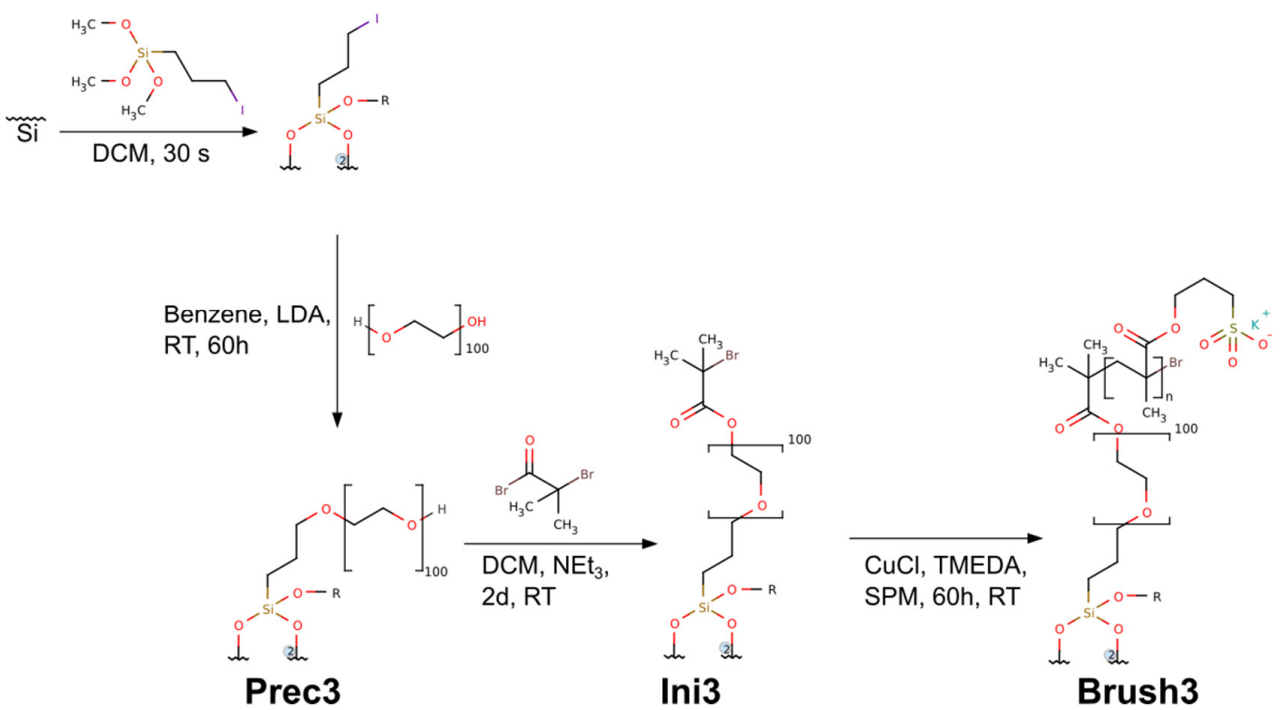

Figure 1. Synthetic route towards the brushes used in this study.

\subsection{Precursors-Prec1, Prec2, Prec3}

The precursors Prec1 and Prec2 were grafted to the silicon surfaces using the same strategy for all samples. At the bottom of a $15 \mathrm{~mL}$ centrifuge tube $30 \mu \mathrm{L}$ of 3-aminopropyltrimethoxysilane (Prec1) or $\mathrm{N}$-methylaminopropyl trimethoxysilane (Prec2) were deposited. Then, the activated wafers (after the piranha solution treatment) were exposed to the precursor vapor by placing them perpendicularly on top of the precursor in the centrifuge tube without touching the liquid. After $3 \mathrm{~h}$ at $30^{\circ} \mathrm{C}$ the wafers were removed and rinsed with copious amounts of ethanol, chloroform, ethanol, ultrapure water, and finally dried in a stream of argon. If not used immediately, the wafers were stored in deionized water.

Prec3 was obtained by covering a freshly prepared wafer with 3-iodopropyl trimethoxysilane for $2 \mathrm{~min}$ followed by generously rinsing the wafer with ethanol, chloroform, ethanol, and ultrapure water before drying in a stream of argon. If not used immediately, the wafer was stored in deionized water. Subsequently, the dry wafers were inserted into $15 \mathrm{~mL}$ centrifuge tubes filled with dry benzene to completely cover the wafers. After the addition of $100 \mathrm{mg}$ of PEO4600, the tube was closed and shaken for $2 \mathrm{~min}$ to dissolve the polymer. Then $100 \mu \mathrm{L}$ of $2 \mathrm{M}$ LDA solution in THF was added and the 
closed tube was shaken for $5 \mathrm{~s}$ and allowed to stand for $60 \mathrm{~h}$. The wafers were removed from the now brown liquid and generously rinsed with ethanol, chloroform, ethanol, and water and finally dried in a stream of argon.

\subsection{ATRP Initiators-Ini1, Ini2, Ini3}

The ATRP initiators Ini1, Ini2 and Ini3 were obtained using an identical procedure. A wafer covered with a monolayer of a given precursor (Prec1, Prec2, or Prec3) was immersed in $3 \mathrm{~mL}$ of dry DCM or chloroform in a $15 \mathrm{~mL}$ centrifuge tube. Then $139 \mu \mathrm{L}$ of triethylamine and $123 \mu \mathrm{L}$ of $\alpha$-bromoisobutyryl bromide were added. The tube was closed, shaken, and left for $60 \mathrm{~h}$ for reaction completion at room temperature. After removal from the liquid, the wafer was generously rinsed with ethanol, chloroform, ethanol, and ultrapure water. If not used immediately the wafer was stored in deionized water.

\subsection{Brushes-Brush1, Brush2, Brush3}

All polymer brushes Brush1, Brush2, Brush3 were synthesized with the same strategy using an established protocol $[15,18]$. A $5 \mathrm{~mL}$ screw lid vial was cleaned with concentrated nitric acid $(69 \%)$ and ultrapure water just before use. Thereafter a dry, initiator-modified wafer (Ini1, Ini2, Ini3) was deposited in the clean vial and the vial was closed with a septum. Subsequently $1 \mathrm{~g}$ of SPM and $11 \mu \mathrm{L}$ of TMEDA were dissolved in a second vial in $1 \mathrm{~mL}$ of ultrapure water and the solution was deoxygenated for $5 \mathrm{~min}$ with argon. Afterwards, the solution was transferred to a vial containing $10 \mathrm{mg}$ of copper(I) chloride. This mixture was stirred vigorously until the copper(I) chloride was completely dissolved. This solution was then transferred to the first vial containing the wafer. After $12 \mathrm{~h}$ at room temperature the wafer was removed and generously rinsed with ultrapure water before immersing it into a vial of ultrapure water for an hour. Finally, the wafer was again rinsed with ultrapure water and dried in a stream of argon. If not used immediately, the samples were again stored in water. Figure 1 shows the route for brush synthesis.

\subsection{Mineralization-Min1, Min2, Min3}

Mineralization of the brushes was achieved using an identical approach for all samples Min1, Min2, and Min3 [15,18]. In brief, for mineralization, $15 \mathrm{~mL}$ of the Ca-containing component of doubly concentrated simulated body fluid (Ca-2SBF) and $15 \mathrm{~mL}$ of the phosphate component of doubly concentrated SBF (P-2SBF) were mixed and stirred. Then a wafer was placed at the center of the reaction vessel with the brush side facing downwards to avoid sedimentation of $\mathrm{CP}$ formed in solution onto the brush surfaces. After ca. $5 \mathrm{~min}, 2.5 \mathrm{~mL}$ of a $0.1 \mathrm{M} \mathrm{CaCl}_{2}$ solution were added without stirring to induce mineral formation. After $24 \mathrm{~h}$, the wafer was removed from the solution and residual liquid on the wafer was removed with a stream of argon, but the wafer was not dried completely at this step. Afterwards, the wafer was rinsed generously with distilled water and dried in a stream of argon. The entire mineralization procedure was repeated once to ensure uniform mineralization.

\subsection{Atomic Force Microscopy (AFM)}

AFM experiments were done in air on a MultiMode (Bruker, Poznan, Poland) microscope working in tapping ${ }^{\circledR}$ mode (silicon cantilevers with a nominal spring constant of $40 \mathrm{~N} \mathrm{~m}^{-1}$ ) and on a Dimension Icon (Bruker, Poznan, Poland) microscope working in the PeakForce $\mathrm{QNM}^{\circledR}$-Mode (silicon cantilevers with a nominal spring constant of $0.4 \mathrm{~N} \mathrm{~m}^{-1}$ ). The dry thicknesses of the brushes were determined using the AFM height measurements at the edges of scratches formed in the brush layers using tweezers. For image analysis, processing, and presentation GWYDDION 2.34 [19] (http:/ / gwyddion.net/) was used. Thickness determination on scratched surfaces [20,21] was repeated 9-10 times for Brush1 and Brush2. Brush3 samples were highly inhomogeneous and thickness measurements were not reproducible. All samples were rinsed with ultrapure water and dried with nitrogen before analysis. 


\subsection{Contact Angle Measurements}

Contact angle measurements were done on a KSV-CAM 100 contact angle meter (KSV Instruments, Helsinki, Finland). Before analysis, the samples were rinsed with water and dried with nitrogen or argon.

\subsection{Scanning Electron Microscopy (SEM)}

SEM was done on a JEOL JSM-6510 (Freising, Germany) with a tungsten filament. All measurements were performed at $0.5-30 \mathrm{kV}$. All samples were carbon-coated prior to imaging using a POLARON CC7650 carbon coater. All samples were glued on an aluminum sample holder using a conductive glue-pad (Plano) and the sample and the sample holder were electrically contacted by copper tape to avoid or at least reduce sample charging because charging of such non-conductive samples is very common.

\subsection{Infrared Reflection Absorption Spectroscopy (IRRAS)}

IRRAS data were obtained on a Nicolet iS10 spectrometer with grazing-angle reflectance accessory set at $84^{\circ}$ for all measurements. Spectra were measured from 650 to $4000 \mathrm{~cm}^{-1}$ using 512 scans for averaging and a resolution of $8 \mathrm{~cm}^{-1}$. Before analysis, all samples were rinsed with water and dried with argon.

\subsection{X-Ray Photoelectron Spectroscopy (XPS)}

XPS measurements were performed using a K-Alpha+ instrument (ThermoFisher Scientific, East Grinstead, UK). Data acquisition and processing using the Thermo Avantage software is described elsewhere [22]. All samples were analyzed using a micro-focused, monochromated Al K $\alpha$ X-ray source (400 $\mu \mathrm{m}$ spot size). The K-Alpha charge compensation system was employed during analysis, using electrons of $8 \mathrm{eV}$ energy and low-energy argon ions to prevent any localized charge build-up. The spectra were fitted with one or more Voigt profiles (binding energy uncertainty: $\pm 0.2 \mathrm{eV}$ ). The analyzer transmission function, Scofield sensitivity factors [23], and effective attenuation lengths (EALs) for photoelectrons were applied for quantification. EALs were calculated using the standard TPP-2M formalism [24].

All spectra were referenced to the $\mathrm{C} 1$ s peak of hydrocarbon at $285.0 \mathrm{eV}$ binding energy controlled by means of the well-known photoelectron peaks of metallic $\mathrm{Cu}, \mathrm{Ag}$, and $\mathrm{Au}$. Sputter depth profiles were performed using a raster scanned $\mathrm{Ar}+$ ion beam at $1.0 \mathrm{keV}$ and $30^{\circ}$ angle of incidence.

\subsection{Cell Culture Experiments}

Dictyostelium discoideum cells expressing the green fluorescent GFP-Lim $\Delta$ coil fusion protein [25] were cultivated on mineralized and unmineralized wafers at $21^{\circ} \mathrm{C}$ in HL5c medium (Formedium, Hunsanton, UK). All samples were incubated for $60 \mathrm{~h}$; then the adhering cells were fixed with glutaraldehyde (0.5\%) [26]. Actin appears green as GFP-Limcoil fusion protein binds to F-actin. Microtubules were visualized in red using the monoclonal anti- $\alpha$-tubulin antibody YL1/2 and the anti-rat-antibody AlexaFluor-568. Cell nuclei were labeled in blue with $4^{\prime}, 6$-diamidino-2-phenylindol dihydrochloride (DAPI). N-propylgallate (2\%) was used as anti-bleaching agent and samples were mounted in Mowiol [26]. Wide-field microscopy was done on a Zeiss CellObserver HS/Axiovert $200 \mathrm{M}$ system with a PlanApo $100 \times / 1.4$ N.A. Lens and an Axiocam MRm Rev. 3 CCD Camera. z-Stacks were recorded at a distance of $0.25 \mu \mathrm{m}$. Iterative deconvolution of microscopic images with a measured point spread function was performed with Zeiss Axiovision 4.8. Data analysis was carried out with ImageJ 1.48k (Rasband, W.S., ImageJ, U.S. National Institutes of Health, Bethesda, MD, USA, http://imagej.nih.gov/ij/, 1997-2014.) 


\subsection{IRRAS of Brush1, Brush2, Brush3, Min1, Min2, Min3}

Brush1. IRRAS: $2960 \mathrm{~cm}^{-1}, \mathrm{C}-\mathrm{H}$ asymmetric stretching vibration; $2897 \mathrm{~cm}^{-1}, \mathrm{C}-\mathrm{H}$ symmetric stretching vibration; $1725 \mathrm{~cm}^{-1}, \mathrm{C}=\mathrm{O}$ stretching vibration of saturated ester; $1448 \mathrm{~cm}^{-1}, \mathrm{C}-\mathrm{H}$ asymmetric deformation of $\mathrm{CH}_{3} ; 1475 \mathrm{~cm}^{-1}$ shoulder, $\mathrm{C}-\mathrm{H}$ symmetric deformation of $\mathrm{CH}_{3} ; 1262 \mathrm{~cm}^{-1}$, symmetrical Si-C bending [27-29] $1190 \mathrm{~cm}^{-1}$, symmetric stretching vibration of $\mathrm{SO}_{3} ; 1107 \mathrm{~cm}^{-1}$ $\mathrm{Si}-\mathrm{O}-\mathrm{Si}$ stretching [27-29]; $1048 \mathrm{~cm}^{-1}$, asymmetric stretching vibration of $\mathrm{SO}_{3}$. Molecular weights $\left(\mathrm{M}_{\mathrm{W}}\right)$ of the individual polymer chains could not be determined; for $\mathrm{M}_{\mathrm{W}}$ determination the polymers would need to be removed from the surfaces; this is particularly difficult with the rather heterogeneous Brush3, but is problematic for all samples.

Brush2. IRRAS: $2960 \mathrm{~cm}^{-1}, \mathrm{C}-\mathrm{H}$ asymmetric stretching vibration; $2897 \mathrm{~cm}^{-1}, \mathrm{C}-\mathrm{H}$ symmetric stretching vibration; $1725 \mathrm{~cm}^{-1}, \mathrm{C}=\mathrm{O}$ stretching vibration of saturated ester; $1448 \mathrm{~cm}^{-1}, \mathrm{C}-\mathrm{H}$ asymmetric deformation of $\mathrm{CH}_{3} ; 1475 \mathrm{~cm}^{-1}, \mathrm{C}-\mathrm{H}$ symmetric deformation of $\mathrm{CH}_{3} ; 1246 \mathrm{~cm}^{-1}$, symmetrical Si-C bending [27-29]; $1215 \mathrm{~cm}^{-1}$, symmetric stretching vibration of $\mathrm{SO}_{3} ; 1107 \mathrm{~cm}^{-1}$ Si-O-Si stretching [27,28]; $1048 \mathrm{~cm}^{-1}$, asymmetric stretching vibration of $\mathrm{SO}_{3}$.

Brush3. IRRAS: $2960 \mathrm{~cm}^{-1}, \mathrm{C}-\mathrm{H}$ asymmetric stretching vibration; $2897 \mathrm{~cm}^{-1}, \mathrm{C}-\mathrm{H}$ symmetric stretching vibration; $1725 \mathrm{~cm}^{-1}, \mathrm{C}=\mathrm{O}$ stretching vibration of saturated ester; $1448 \mathrm{~cm}^{-1}, \mathrm{C}-\mathrm{H}$ asymmetric deformation of $\mathrm{CH}_{3} ; 1263 \mathrm{~cm}^{-1}$, symmetrical Si-C bending [27-29]; $1190 \mathrm{~cm}^{-1}$, symmetric stretching vibration of $\mathrm{SO}_{3} ; 1107 \mathrm{~cm}^{-1} \mathrm{Si}-\mathrm{O}-\mathrm{Si}$ stretching $[27,28] ; 1048 \mathrm{~cm}^{-1}$, asymmetric stretching vibration of $\mathrm{SO}_{3}$.

Min1. IRRAS: $1726 \mathrm{~cm}^{-1}, \mathrm{C}=\mathrm{O}$ vibration; $1107 \mathrm{~cm}^{-1} v_{3}-\mathrm{PO}_{4}{ }^{3-}$ vibration of phosphates [30-32] $1445 \mathrm{~cm}^{-1} v_{3}$ vibrations of $\mathrm{CO}_{3}{ }^{2-}$ [30-32] $893 \mathrm{~cm}^{-1} v_{2}$ vibrations of $\mathrm{CO}_{3}{ }^{2-}[30,31]$.

Min2. IRRAS: $1726 \mathrm{~cm}^{-1}, \mathrm{C}=\mathrm{O}$ vibration; $1109 \mathrm{~cm}^{-1}, \mathrm{PO}_{4}{ }^{3-} v_{3}$ vibration of phosphates [30-32]; $1416 \mathrm{~cm}^{-1}, v_{3}$ of $\mathrm{CO}_{3}{ }^{2-}$ [30-32]; $903 \mathrm{~cm}^{-1}$, A-type $\mathrm{CO}_{3}{ }^{2-}$ substitution of apatites [30,31]; $871 \mathrm{~cm}^{-1}$, B-type $\mathrm{CO}_{3}{ }^{2-}$ substitution of apatites [30,31].

Min3. IRRAS: $1490 \mathrm{~cm}^{-1} v_{3}$ of carbonate [30,31]; $1043 \mathrm{~cm}^{-1} v_{3}-\mathrm{PO}_{4}{ }^{3-}$ vibration of phosphates [30-32]; $862 \mathrm{~cm}^{-1} v_{2}$ of $\mathrm{CO}_{3}{ }^{2-}[30,31]$.

\section{Results}

\subsection{Polymer Brushes}

Contact angle (CA) measurements were used to assess the surface modifications (Table 1). CA measurements provide qualitative insight into the surface modification. Prec1 and Prec2 have CA values of around $20^{\circ}$ indicating a rather hydrophilic surface. After modification to Ini1 or Ini2, the surfaces become more hydrophobic with CAs values of ca. $75^{\circ}$. Finally, after polymerization, the CA is again lower $\left(\mathrm{ca} .7^{\circ}\right)$, proving that the polymerization reaction leads to a hydrophilic surface.

Prec 3 is slightly different in that the CA is ca. $15^{\circ}$, which is slightly lower than the $20^{\circ}$ found for Prec1 and Prec2. Consistent with this observation, the CA of Ini3 is ca. 50 . This is again lower than what is observed for Ini1 and Ini2. After polymerization of the anionic brush, however, the CA is also $7^{\circ}$, identical to the Brush1 and Brush2 surfaces.

Brush thickness was determined via AFM on scratched surfaces; thicknesses are given in Table 1. Brush1 and Brush2 exhibit similar thicknesses (ca. 80-90 nm) while the largest variation is observed for Brush3.

The somewhat different behavior of Brush3 compared to the other brushes is further confirmed when the efficiency of the surface modification is considered. All polymerization reactions work, but various samples of Brush3 often exhibit (on the same wafer) individual regions that contain the polymer brush while other regions on the same wafer are not (fully) covered with the brush. Overall, only ca. $50 \%$ of the Brush 3 wafers afford optically faultless and homogeneously covered wafer surfaces. It is likely due to non-uniform attachment of PEO to the surface producing an inhomogenous distribution of the subsequently attached ATRP initiator on the surface. To exclude artifacts in the 
data by non-uniform surfaces, only completely covered and homogeneous samples where used for the subsequent experiments.

Table 1. Contact angle values and film thicknesses as determined using atomic force microscopy (AFM).

\begin{tabular}{cccccccccc}
\hline Identifier & Prec1 & Ini1 & Brush1 & Prec2 & Ini2 & Brush2 & Prec3 & Ini3 & Brush3 \\
\hline Contact angle $\left(^{\circ}\right)$ & $20 \pm 10$ & $75 \pm 5$ & $7 \pm 5$ & $20 \pm 10$ & $75 \pm 5$ & $7 \pm 5$ & $15 \pm 5$ & $50 \pm 5$ & $7 \pm 5$ \\
\hline Thickness by AFM $(\mathrm{nm})$ & & & $78 \pm 6$ & & $92 \pm 10$ & & & $30-300^{1}$ \\
\hline
\end{tabular}

${ }^{1}$ The thicknesses of Brush3 vary significantly between samples; we therefore only provide a thickness range.

Figure 2 shows AFM images of all brushes used in this study. Brush1 and Brush2 are quite similar in terms of the overall appearance of the surface morphology and thickness (see above). This is indicated by similar roughness values $\left(\mathrm{R}_{\mathrm{a}}=0.3 \mathrm{~nm}\right.$ for Brush1 and $0.12 \mathrm{~nm}$ for Brush2). AFM results, therefore, suggest that the difference between the starting groups-one additional methyl group in case of Brush2-does not significantly affect the overall polymerization reaction.

However, as stated above, Brush3 shows much less reproducible results in spite of identical conditions used for polymerization; Figure 2 therefore shows two different brushes of this type. One brush is very thin with $30 \mathrm{~nm}$ thickness and the other one is much thicker (ca. $300 \mathrm{~nm}$ ). The thinner sample is very smooth while the thicker one is very rough with $R_{a}$ value as high as $26 \mathrm{~nm}$ for $2 \times 2 \mu \mathrm{m}^{2}$ image.

In contrast to the thin Brush3, the thick Brush3 samples resemble Brush1 and Brush2 in that also here we observe micrometer-sized blobs; these blobs are however much larger in diameter than the features observed in Brush1 and Brush2. Moreover, the entire material appears rougher and the height differences observed in these samples reach about $200 \mathrm{~nm}$.

These observations are supported by detailed surface roughness analyses (Table S1): $R_{a}=0.3 \mathrm{~nm}$ for Brush1, $R_{a}=0.12 \mathrm{~nm}$ for Brush2, and $R_{a}=0.12 \mathrm{~nm}$ for Brush3 (30 nm thickness), and $R_{a}=26 \mathrm{~nm}$ for Brush3 $(300 \mathrm{~nm})$.

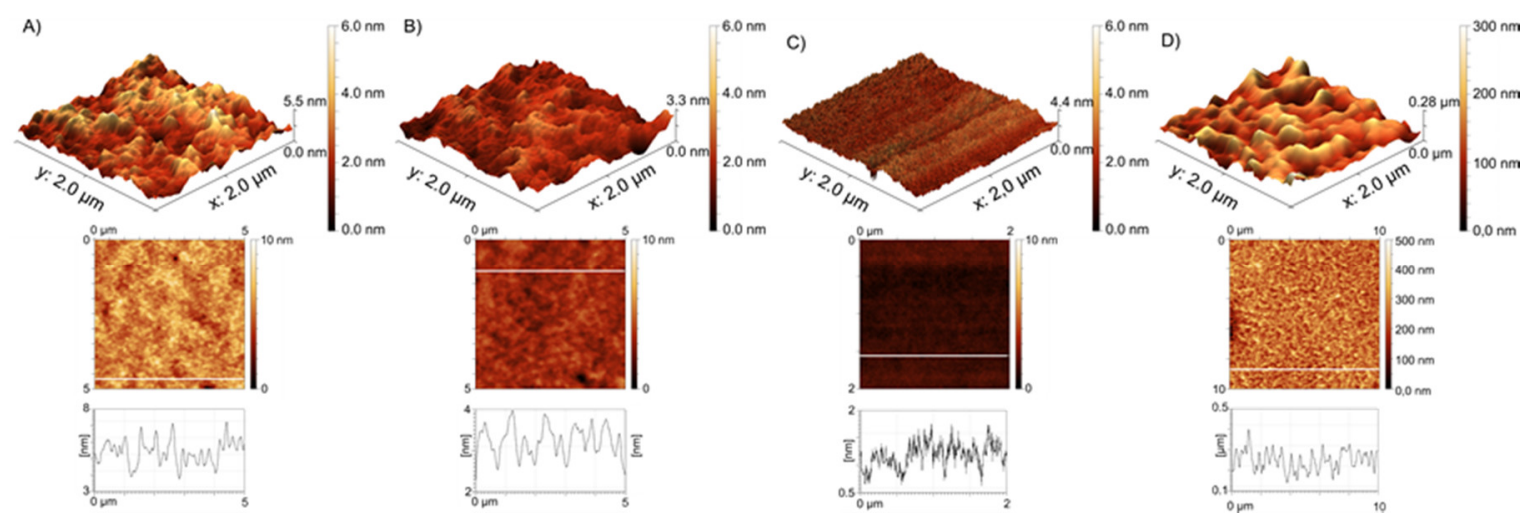

Figure 2. 3D AFM topographic views (top row), height images (middle row), and example height profiles (bottom) of (A) Brush1 $\left(R_{a}=0.3 \mathrm{~nm} ; R_{z}=1.64 \mathrm{~nm}\right) ;(B) \operatorname{Brush} 2\left(R_{a}=0.12 \mathrm{~nm} ; R_{z}=0.61 \mathrm{~nm}\right)$; (C) Brush3 with a thickness of $30 \mathrm{~nm}\left(\mathrm{R}_{\mathrm{a}}=0.12 \mathrm{~nm} ; \mathrm{R}_{\mathrm{z}}=0.69 \mathrm{~nm}\right)$; and (D) Brush3 with a thickness of $300 \mathrm{~nm}\left(\mathrm{R}_{\mathrm{a}}=26 \mathrm{~nm} ; \mathrm{R}_{\mathrm{z}}=154 \mathrm{~nm}\right)$. A detailed analysis can be found in the supporting information.

The polymer brushes were further characterized with IRRAS. Figure 3 shows representative IRRA spectra along with a Fourier-transform infrared (FTIR) spectrum of the free (i.e., not grafted to the surface) PSPM polymer made from the same monomer [15]. All characteristic IR signals of the free PSPM polymer can also be found in the spectra of the brushes. The IRRA spectra show no bands that could be assigned to the initiator moieties. This is likely due to the very low concentration of initiator groups compared to the number of monomer units in the brushes. In the case of the brushes grafted from the PEO-based initiators (Brush3) we have observed increased absorption from $\mathrm{C}-\mathrm{H}$ 
stretching vibrations in $\mathrm{CH}_{2}$ groups $\left(2933 \mathrm{~cm}^{-1}\right)$ when compared to the spectra for Brush1 and Brush2 (see Figure 3). However, virtually no changes could be observed in the region $1000-1300 \mathrm{~cm}^{-1}$ due to strong absorption of the PSPM brush and the underlying silicon dioxide.

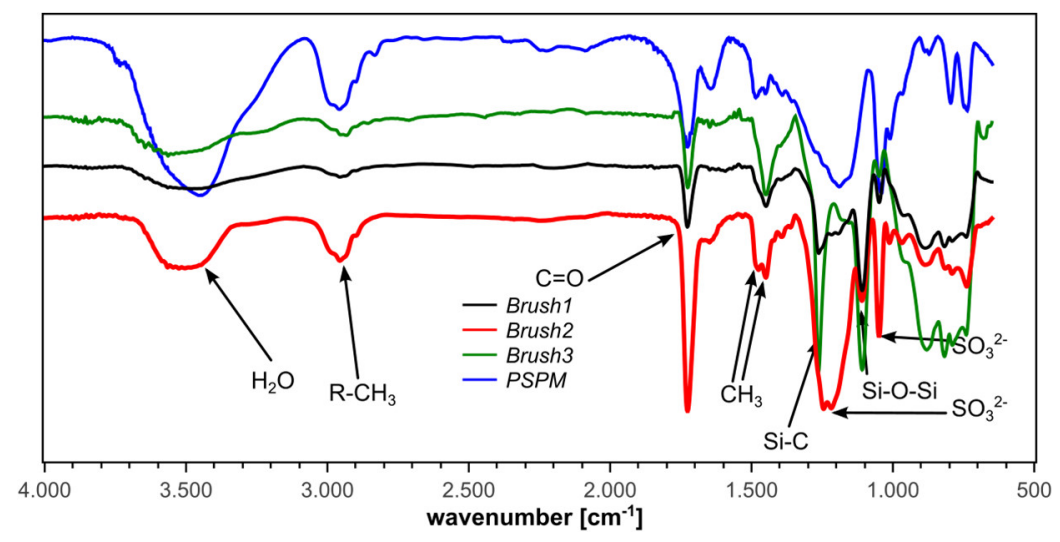

Figure 3. Infrared reflection absorption spectra (IRRAS) of the polymer brushes Brush1, Brush2, Brush3, and a Fourier-transform infrared (FTIR) spectrum of free (non-surface-grafted) poly(3-sulfopropyl methacrylate) potassium salt (PSPM) for comparison.

Besides the bands originating from the brushes, all IRRA spectra show $\mathrm{Si}-\mathrm{O}-\mathrm{Si}$ vibration bands at $1107 \mathrm{~cm}^{-1}$ and $\mathrm{Si}-\mathrm{C}$ bands at $1263 \mathrm{~cm}^{-1}$. These vibrations are commonly very strong [33-35] and can be assigned to silicon dioxide surface layers and the silane groups in the precursors on the silicon wafer surface, respectively. Possibly, this vibration can also be assigned to a $\mathrm{C}-\mathrm{O}-\mathrm{C}$ vibration.

\subsection{Mineralization of Polymer Brushes}

As stated in the introduction, polymer brushes are interesting for (i) studying fundamental processes in (bio)mineral formation and (ii) application in biomaterials technology, in particular surface design. As a result, we have studied the ability of the polymer brushes to induce and control calcium phosphate (CP) formation. Indeed, visual inspection after mineralization shows that all samples appear optically homogeneous and are covered with a white layer of mineral.

Attempts to analyze the sample surfaces via scanning electron microscopy (SEM) or energy dispersive X-ray spectroscopy (EDXS) fail due to rapid sample charging and sample destruction. AFM fails as the samples are too rough. X-ray diffraction (XRD) only produces very noisy patterns with low count rates that cannot be analyzed further. This is consistent with earlier results on similar materials $[4,5,7,8]$ and can be assigned to the often very low order in these materials in addition to very low sample amounts.

XPS was therefore used to determine the chemical composition (however not the crystal phase) of the mineral deposits on the surfaces (see Figure S2, Supporting Information). Especially the calcium to phosphorus $(\mathrm{Ca} / \mathrm{P})$ ratio is a useful parameter to (qualitatively) differentiate some of the CPs that may possibly be contained in the mineral films [36-38].

The $\mathrm{C} 1 \mathrm{~s}$ components observed in the XPS spectra at 285.0, 286.3, and $288.9 \mathrm{eV}$ are attributed to $\mathrm{C}-\mathrm{H}, \mathrm{C}-\mathrm{O}$, and $\mathrm{COO}$ groups, respectively. In combination with the corresponding $\mathrm{O} 1 \mathrm{~s}$ peaks at $532.2 \mathrm{eV}(\underline{\mathrm{O}}=\mathrm{C}-\mathrm{O}-\mathrm{C})$ and $533.5 \mathrm{eV}(\mathrm{O}=\mathrm{C}-\underline{\mathrm{O}}-\mathrm{C})$ as well as the $\mathrm{S} 2 \mathrm{p}_{3 / 2}$ at $168.3 \mathrm{eV}\left(\mathrm{SO}_{3}{ }^{-}\right.$groups $)$ these findings clearly prove the presence of the polymer brushes [39,40]. Additionally, calcium $\left(\mathrm{Ca} 2 \mathrm{p}_{3 / 2}=347.5 \mathrm{eV}\right)$ and phosphate $\left(\mathrm{P} 2 \mathrm{p}_{3 / 2}=133.2 \mathrm{eV}, \mathrm{O} 1 \mathrm{~s}=531.1 \mathrm{eV}\right)$ components can clearly be identified proving the successful formation of calcium phosphate within the polymer brushes [41].

Figure S2 in the supporting information shows an example of the C 1s, O 1s, Ca 2p, S 2p, and P 2p XP spectra of a Min1 surface. However, in the case of Min3 weak $\mathrm{Si} 2 \mathrm{p}$ peaks of $\mathrm{Si}$ and $\mathrm{SiO}_{\mathrm{x}}$ at 99.0 and $102.7 \mathrm{eV}$, respectively, can be detected. They originate from the substrate. This corroborates the IRRAS findings and indicates a certain inhomogeneous distribution of the brushes. 
All samples contain calcium, sulfur as sulfate, phosphorous as phosphate, carbon as $\mathrm{C}-\mathrm{H}$ and $\mathrm{C}-\mathrm{O} / \mathrm{C}-\mathrm{N}$ moieties along with oxygen as $\mathrm{P}-\mathrm{O}, \mathrm{C}=\mathrm{O}, \mathrm{SiO}_{\mathrm{x}}$, and $\mathrm{O}=\mathrm{C}-\mathrm{O}$ compounds. In the case of Min3, also silicon as $\mathrm{Si}$ and $\mathrm{SiO}_{x}$ is detected, consistent with the IRRAS measurements described above. All samples show slight $\mathrm{Na}$ and $\mathrm{Mg}$ impurities. The $\mathrm{Ca} / \mathrm{P}$ ratio determined for the entire surface is 1.92 and 1.93 for Min1 and Min3, while the ratio is 1.50 in Min2.

XPS sputter depth profiles were acquired for all mineralized samples. The rapidly increasing intensity of the bulk Si signal again indicates an inhomogeneous brush density and, therefore, it is impossible to estimate layer thicknesses. In consequence, the linear sputter time scale (rather than a nanometer scale) was retained as $\mathrm{x}$-axis.

As more and more of the layer is removed and the measurement approaches the silicon substrate surface, XPS detects an increasing sulfur content (originating from the sulfonate groups in the polymer). Similarly, all samples show a high $\mathrm{Ca}, \mathrm{P}$, and $\mathrm{O}$ concentration at the topmost surface, which gradually decreases towards the surface of the $\mathrm{Si}$ wafer. The carbon signal shows relatively high $\mathrm{C}$ concentrations at the sample surface mainly due to adventitious carbon and then decreases in a two-step decay to below $5 \%$, in some samples below ca. $2 \%$ towards the silicon wafer surface.

Note that XPS experiments do not detect copper signals from the polymerization reaction. This is consistent with previous data $[15,18]$ showing that the $\mathrm{CuCl}$ catalyst is removed to below the detection limit of the XPS.

Based on the elemental composition profiles shown in Figure $4 \mathrm{Ca} / \mathrm{P}$ concentration ratios vs. sputter depth were calculated for the three samples types. Figure 5 shows that indeed there is a variation of the $\mathrm{Ca} / \mathrm{P}$ ratio vs. sample depth. Moreover, there are also variations between the three types of polymer brushes. Min1 shows two regimes within the $\mathrm{Ca} / \mathrm{P}$ ratio: (i) close to the surface the $\mathrm{Ca} / \mathrm{P}$ ratio is around 1.7 but rapidly rises to ca. 2 . After this initial increase, no further significant changes are observed until very close to the $\mathrm{Si}$ surface, where a small increase is observed once again.

A)

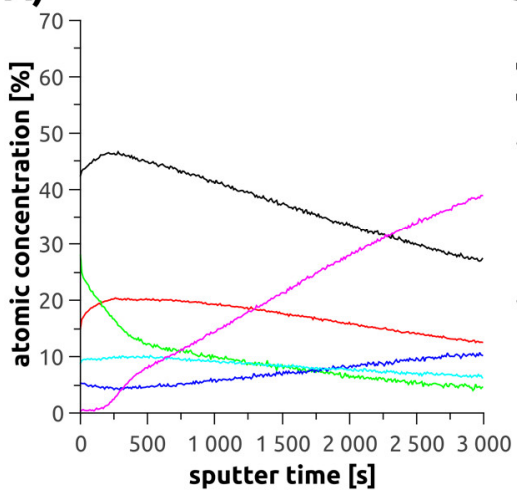

B)

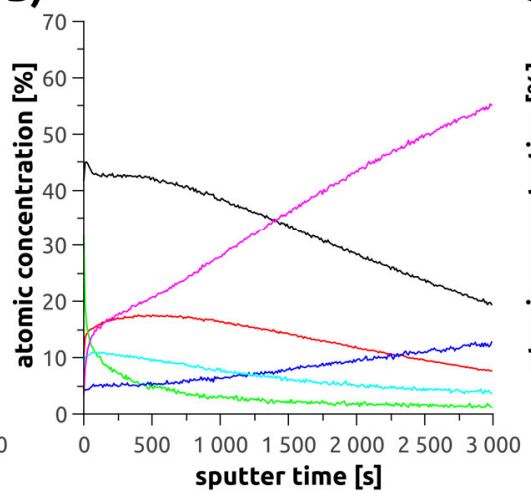

C)

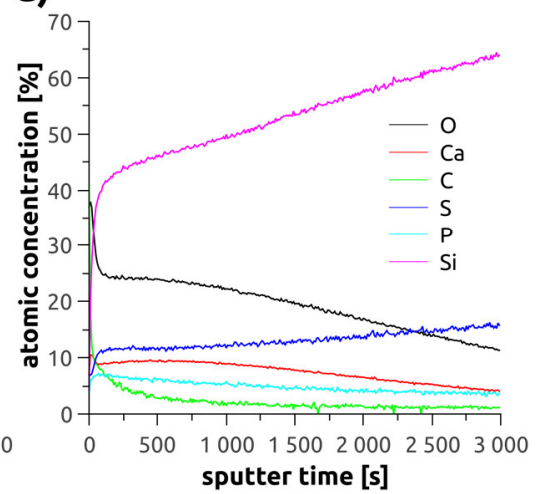

Figure 4. X-ray photoelectron spectroscopy (XPS) sputter depth profiles of the mineralized polymer brushes (A) Min1, (B) Min2, and (C) Min3. XPS raw data are summarized in the supporting information (Table S2).

Min2 samples are much more heterogeneous. The $\mathrm{Ca} / \mathrm{P}$ ratio begins at just below 1.4 at the sample surface and increases to 2.4 before decreasing again to about 2 close to the Si surface. Very close to the Si surface, we observe the same small, but noticeable increase already described for Min1.

Min3 samples are again different from the samples described above because here the initial $\mathrm{Ca} / \mathrm{P}$ ratio close to the surface is about 1.9 , but then rapidly decreases to 1.4 . It subsequently increases again to ca. 1.6 and then decreases to a very low value of ca. 1.2 close to the Si surface. 


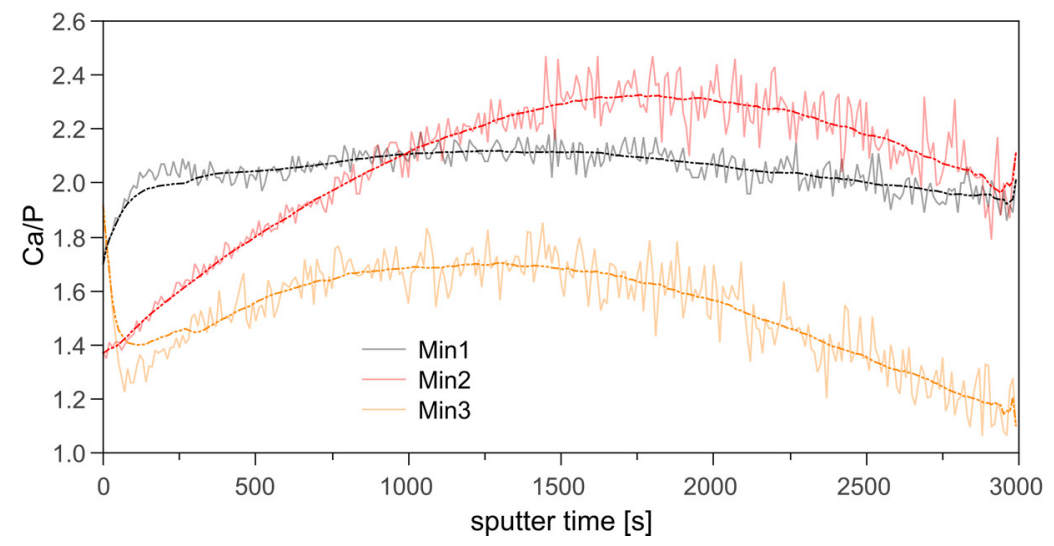

Figure 5. Ca/P ratios of Min1, Min2, and Min3 vs. sputter time calculated from the respective XPS sputter depth profiles in Figure 4: solid lines represent the experimental data; dash-and-dot lines are the respective sliding averages from the experimental data.

As shown above, XPS seems to indicate some composition variation vs. film depth. This may be assigned to the fact that the current materials are rather complex and may indeed not be entirely homogeneous throughout the entire sample depth. In principle one could use carbon or sulfur signals but XPS spectra acquired from mineralized samples also contain other elements and represent a highly complex matrix with local heterogeneities in both the films and the mineral components. Moreover, since IRRAS data (see below) suggest the formation of carbonated apatite, the carbon signal in the XPS spectra cannot solely be assigned to the polymer, which further complicates the analysis.

As stated above, XRD analysis of the samples to assign (crystal) phases is not possible. However, IRRAS analysis of the samples shows several bands that can be used for a qualitative phase assignment of the mineral phases within the polymer brushes.

Figure 6 shows representative IRRAS data of Min1, Min2, and Min3. The broad signal observed at $1107 \mathrm{~cm}^{-1}$ in the spectra of Min1 is due to the $v_{3}-\mathrm{PO}_{4}{ }^{3-}$ vibration of apatites; possibly this signal overlaps with a Si-O-Si signal that also occurs at this position. Additional bands at 1445 and $893 \mathrm{~cm}^{-1}$ can be assigned to the $v_{2}$ and $v_{3}$ vibrations of $\mathrm{CO}_{3}{ }^{2-}[30,31]$. Both the width of the $v_{2}$ and the shape of the $v_{3}$ vibrations indicate the presence of carbonate-substituted hydroxyapatite (CHAP) crystallized in AB-type.

IRRAS data of Min2 are similar, but show some differences. Again, the $\mathrm{PO}_{4}{ }^{3-} v_{3}$ vibration is visible at $1109 \mathrm{~cm}^{-1}$ yet the $\mathrm{SO}_{3}$ and $\mathrm{Si}-\mathrm{O}-\mathrm{Si}$ at 1107 and $1263 \mathrm{~cm}^{-1}$ appear stronger than in Min1 and correspondingly two maxima are observed. The $\mathrm{C}=\mathrm{O}$ vibration at $1726 \mathrm{~cm}^{-1}$ indicative of the sulfopropyl moieties of the polymer brush is more distinct than in Min1. Finally, $v_{2}$ vibrations caused by carbonate ions in AB-type CHAP are visible at 871 (B-type substitution) and $903 \mathrm{~cm}^{-1}$ (A-type substitution) of $\mathrm{CO}_{3}{ }^{2-}$. This observation is supported by the shape [31,42-44] of the $v_{3} \mathrm{CO}_{3}{ }^{2-}$ band at $1416 \mathrm{~cm}^{-1}$. The reason for this observation may be a somewhat higher flexibility or mobility of the individual segments in Min2 or to a somewhat higher crystalline order leading to more defined vibrational modes, but this is not entirely clear at the moment. 

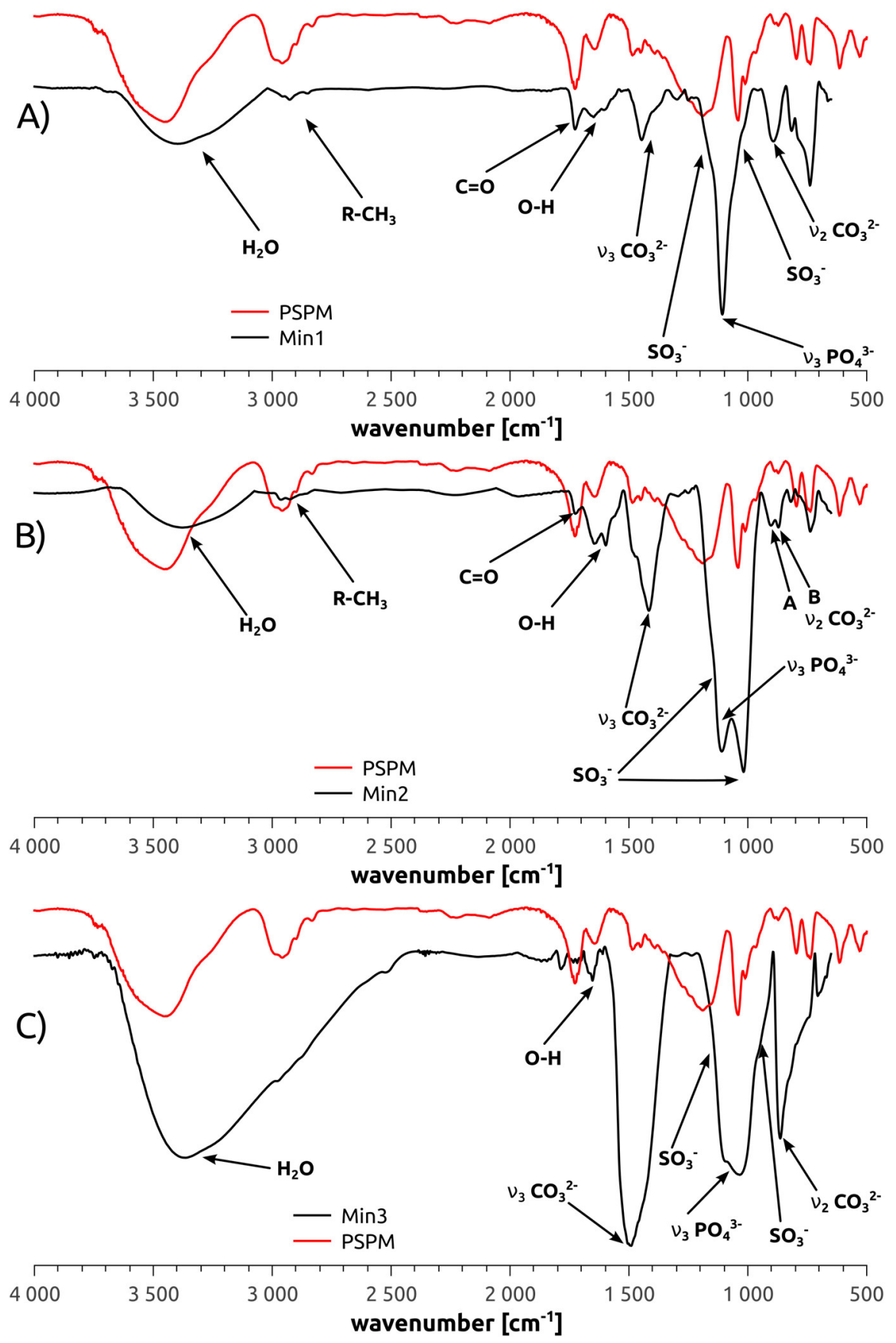

Figure 6. IRRAS data of the mineralized polymer brushes. (A) Min1; (B) Min2 and (C) Min3. PSPM refers to the neat polymer (i.e., polymer not attached to the surface, reproduced from [15] with permission, copyright American Chemical Society, 2014).

IRRAS data of Min3 show more intense carbonate bands at 1490 and $862 \mathrm{~cm}^{-1}$. The $v_{3}$ vibration of $\mathrm{CO}_{3}{ }^{2-}$ is stronger than the phosphate signal at $1043 \mathrm{~cm}^{-1}$. A clear decision whether or not AB-type CHAP is present in Min3 can therefore not be made. This is mostly due to the fact that these bands are very broad. Shoulders on the phosphate band at $\sim 1100 \mathrm{~cm}^{-1}$ can be assigned to $\mathrm{SO}^{3-}$ and $\mathrm{Si}-\mathrm{O}-\mathrm{Si}$ as well.

\subsection{Cell Compatibility of Non-Mineralized and Mineralized Polymer Brushes}

To assess the effect of both the plain and the mineralized brushes on cells, we have studied the behavior of AX2 Dictyostelium discoideum amoebae. Dictyostelium discoideum is a well-established model 
system for eukaryotic cells [45-47]. Three parameters were used as a measure of cell integrity after $60 \mathrm{~h}$ on the hybrid materials: (i) cell morphology, (ii) presence and distribution of the actin skeleton, and (iii) the integrity of the microtubules within the cells.

Figure 7 shows representative fluorescence micrographs of Dictyostelium discoideum on Min3. In all cases of mineralized (Min1, Min2, and Min3) and non-mineralized (Brush1, Brush2, Brush3) brushes the Dictyostelium discoideum amoebae grow attached to our (hybrid) materials, showed the usual actin-rich cell protrusions and macropinocytic cups indicating normal macropinocytosis behavior in liquid medium. Moreover, they show no indications for any disruptions of the actin and the tubulin cytoskeletons compared to control cultures grown in the absence of the hybrid surfaces. This is in contrast to dying cells, which typically round up, form no macropinocytic cups and contain collapsed microtubule cytoskeletons.

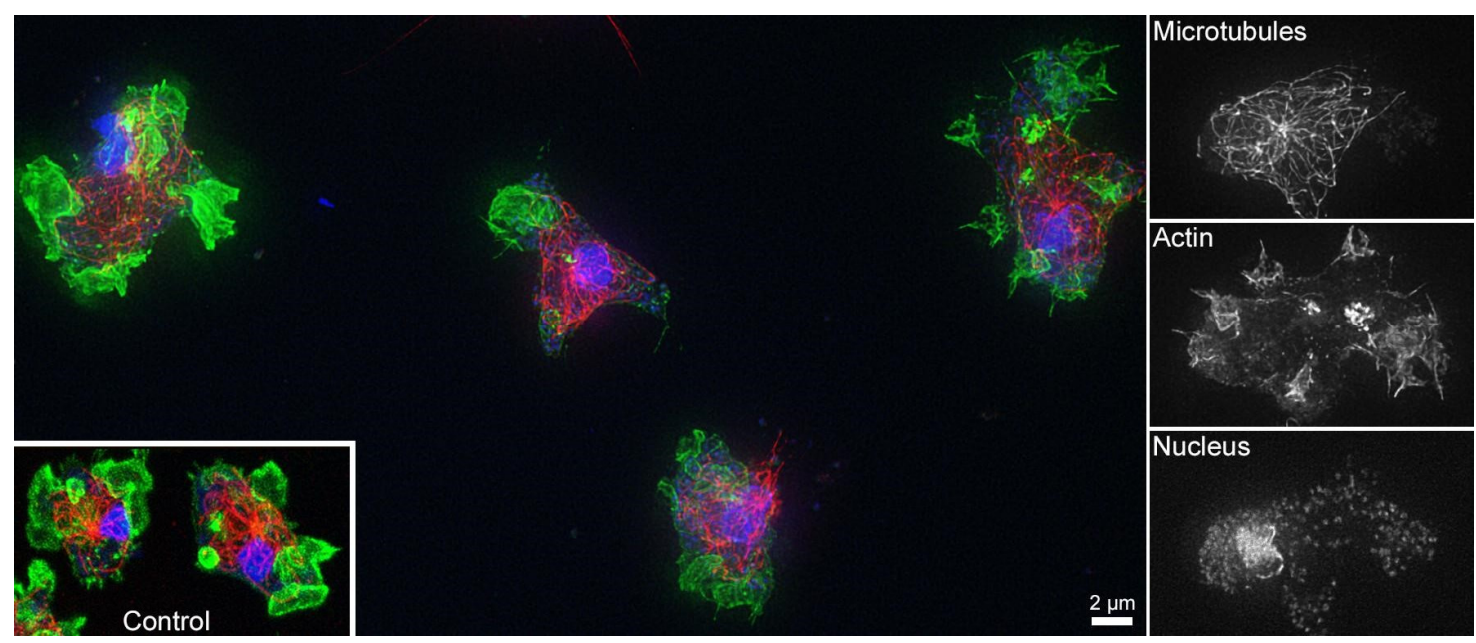

Figure 7. Fluorescence micrographs of Dictyostelium discoideum amoeba on a Min3 surface. Small images to the right show the individual red-green-blue (RGB) channels (rotated by $90^{\circ}$ ) for the cell at the upper right of the composite image showing microtubules (red), actin (green) and nuclei (blue). A representative image of control cells stained accordingly is shown in the inset. The corresponding data on Min1 and Min2 can be found in the supporting information.

\section{Discussion}

As stated in the introduction, understanding surface-controlled mineralization and being able to tailor surfaces are among the key challenges in advanced biomaterials design [9-11,48-53]. The current report contributes to this development and introduces a set of new surfaces that may find application in biomaterials surface development, but also enable the investigation of surface chemistry on $\mathrm{CP}$ deposition.

The synthesis of the polymer brushes is straightforward, but Brush3 shows relatively high surface heterogeneity likely due to non-uniform coverage of the bottom PEO layer that leads to less homogenous distribution of the initiator moieties than in Brush1 and Brush2 [54] (Figure 1, Table 1). It is also possible that the initiating moieties are buried in the PEO layer and hence initiation of the SPM polymerization is less effective which is detrimental to homogeneous polymer brush thickness) [55-57] than in the cases of Brush1 and Brush2.

In spite of these difference, all surfaces induce CP mineral formation suggesting useful applications for studying the above questions on mineral formation and surface design.

Moreover, as hydroxyapatite (HAP) is beneficial to both the reduction of bacterial film formation and cell colonization [58-60]. In addition, as polymer coatings limit bacterial growth on implants $[9,10,12-14]$, the anionic brushes and the $\mathrm{CP} /$ polymer hybrid surfaces introduced here may potentially be useful as dual-use coating inhibiting (i) bacterial growth and (ii) promoting $\mathrm{CP}$ formation; this would enable the surface colonization by human cells. Indeed initial experiments using 
Dictyostelium discoideum amoebae, an established model system for eukaryotic cells [46,47], prove that both the mineral-free brushes and the mineralized surfaces do not interfere with cell growth, overall cell morphology or the appearance of the cytoskeleton, all in all parameters that usually respond very upon toxic stress factors (Figure 7, Figures S2-S7). Moreover, we have shown previously [15] that the same polymers inhibit the formation of $S$. gordonii bacteria on human dental enamel.

AFM (Figure 2) shows that Brush1 and Brush2 surfaces are quite homogeneous and IRRAS data (Figure 6) prove that all brushes are chemically identical to bulk PSPM. The characteristic IRRAS signals confirm the formation of the brushes on the surface. IRRAS and XPS (Figure 4, Figure S1) also prove that the films can be mineralized and that-although there is a slight variation in the $\mathrm{Ca} / \mathrm{P}$ ratios vs. sample depth (Figure 5) - the samples are quite homogeneous in terms of their mineralization levels. Moreover the calcium phosphate deposits formed here are comparable with materials that were grown under similar conditions, including HAP, CHAP, and possibly octacalcium phosphate $[37,38,61,62]$. This is consistent with the $\mathrm{Ca} / \mathrm{P}$ ratios found in XPS, Figure 5 .

Additionally, IRRAS data also provide evidence for $\mathrm{A}-$, $\mathrm{B}-$-, and $\mathrm{AB}$ substitution, mainly in the Min1 and Min2 samples, Figure 6. This is interesting because CHAP, especially AB-substituted CHAP, is enriched over senescence in human bone $[32,60,63-66]$ and teeth $[32,66,67]$. The surfaces introduced here could therefore provide enhanced biocompatibility useful for implant surface modification. On a qualitative level, experiments with Dictyostelium discoideum amoebae support this claim, including the observation that no adverse effects of our materials on the morphology of either the actin, microtubules, or the cell nuclei is evident.

There are only a few studies on mineralized brushes for cell growth $[10,68,69]$ but these studies are mostly based on calcium carbonate rather than calcium phosphate. Letsche et al. [10] found that mesenchymal stem cells predominantly reside in free spaces which were established within the film by photolithography.

Löbbicke et al. [5] reported the first data on poly(methacrylic acid) (PMAA) and (2-dimethyl aminoethyl) methacrylate brushes mineralized with CP. The surfaces show a high mineralization potential; this particularly applies to the PMAA brushes. Moreover, the mineralized brushes showed an enhanced cell proliferation of MC3T3 E1 pre-osteoblasts when compared to the bare non-mineralized brushes.

A similar observation was made by Van den Beucken et al. [70] who used osteoblast-like cells recovered from the bone marrow of rats. Using the layer-by-layer technique (rather than polymer brushes), these authors made coatings from DNA and poly(allylamine) or DNA and poly(D-lysine). After mineralization in $2 \mathrm{SBF}$ a mineral layer was observed but not characterized further. In spite of this, the mineral layer seemed to promote the delivery of osteocalcin into the extracellular matrix in cell culture, indicating that also such a coating could be interesting for biomaterial surface modification. Both the results of the current study and the other data just discussed, therefore, suggest that $\mathrm{CP} /$ polymer hybrid films and surfaces are a key component for the development of high-performance biomaterials surfaces. They could be particularly interesting for surfaces with a projected application in hard tissue implantology. However, in order to completely evaluate the in vitro and in vivo behavior of these surfaces, further experiments will clearly be necessary.

\section{Conclusions}

Polymer brushes based on the SPM monomer are efficient mineralization templates for the formation of $\mathrm{CP}$. The minerals are a mixture of $\mathrm{HAP}$, octacalciumphosphosphate (OCP), and CHAP with various substitution patterns. The current approach has several advantages over existing protocols: (i) the monomer is commercially available and reasonably cost-effective; (ii) the grafting and the polymerization process are straightforward; (iii) the mineral deposition process is simple and efficient; and (iv) viabiliy and morphology of Dictyostelium amoebae, a simple model for motile animal cells, were unaffected by the hybrid surfaces. These factors suggest possible applications in surface design for hard tissue implants such as bone and teeth. 
Supplementary Materials: The following are available online at http:/ /www.mdpi.com/2073-4360/10/10/1165/s1, Table S1: Surface roughness analysis of the polymer brushes, Table S2: Chemical composition of the polymer brushes after mineralization. Figure S1: C 1s. O 1s. Ca 2p. S 2p. and P 2p XPS spectra of a Min1 surface, Figures S2-S7: Fluorescence micrographs of Dictyostelium discoideum amoeba on a Brush1, Brush2, Brush3, Min1, Min2 and Min3 surface, respectively. Small images to the left show the individual RGB channels (rotated by $90^{\circ}$ ) for the cell the image showing microtubules (red), actin (green) and nuclei (blue).

Author Contributions: T.M. made the brushes and performed the mineralization, IRRAS, SEM, EDXS, and CA measurements. K.W. did the IRRAS and AFM experiments including data analysis. A.P.-M. performed the ellipsometry measurements and data analysis. A.K. did additional AFM experiments. R.G. performed the cell culture experiments and data analysis. M.B. performed the XPS experiments and data analysis. T.M., S.Z., and A.T. conceived the experiments, performed data analysis, and wrote the manuscript. All authors contributed to the article writing and correction and approved the final manuscript.

Acknowledgments: The authors thank the European Science Foundation (Precision Polymer Materials P2M, Reference Number 4701), the Karlsruhe Micro- and Nano Facility (Grant No. 2015-014-007830), the University of Potsdam, TEAM program (grant number: TEAM/2016-1/9) of the Foundation for Polish Science co-financed by the European Union under the European Regional Development Fund for financial support. The K-Alpha+ instrument was financially supported by the Federal Ministry of Economics and Technology on the basis of a decision by the German Bundestag.

Conflicts of Interest: The authors declare no conflicts of interest.

\section{References}

1. DESTATIS. Durchschnittliche Weitere Lebenserwartung Nach Altersstufen ab 1871-81 bis 2010-12. 22.04.2015. 2015. Available online: https://www.destatis.de/DE/ZahlenFakten/GesellschaftStaat/Bevoelkerung/ Sterbefaelle/Sterbefaelle.html\#tab194502No2 (accessed on 28 May 2015).

2. Dey, A.; Bomans, P.H.H.; Müller, F.A.; Will, J.; Frederik, P.M.; de With, G.; Sommerdijk, N.A.J.M. The role of prenucleation clusters in surface-induced calcium phosphate crystallization. Nat. Mater. 2010, 9, 1010-1014. [CrossRef] [PubMed]

3. Dey, A.; de With, G.; Sommerdijk, N.J.M. In situ techniques in biomimetic mineralization studies of calcium carbonate. Chem. Soc. Rev. 2010, 39, 397-409. [CrossRef] [PubMed]

4. Hentrich, D.; Junginger, M.; Bruns, M.; Börner, H.G.; Brandt, J.; Brezesinski, G.; Taubert, A. Interface-controlled calcium phosphate mineralization: effect of oligo(aspartic acid)-rich interfaces. CrystEngComm 2015, 17, 6901-6913. [CrossRef]

5. Löbbicke, R.; Chanana, M.; Schlaad, H.; Pilz-Allen, C.; Günter, C.; Möhwald, H.; Taubert, A. Polymer brush controlled bioinspired calcium phosphate mineralization and bone cell growth. Biomacromolecules 2011, 12, 3753-3760. [CrossRef] [PubMed]

6. Zhang, L.-J.; Liu, H.-G.; Feng, X.-S.; Zhang, R.-J.; Zhang, L.; Mu, Y.-D.; Hao, J.-C.; Qian, D.-J.; Lou, Y.-F. Mineralization mechanism of calcium phosphates under three kinds of Langmuir monolayers. Langmuir 2004, 20, 2243-2249. [CrossRef] [PubMed]

7. Hentrich, D.; Brezesinski, G.; Kübel, C.; Bruns, M.; Taubert, A. Cholesteryl Hemisuccinate Monolayers Efficiently Control Calcium Phosphate Nucleation and Growth. Cryst. Growth Des. 2017, 17, 5764-5774. [CrossRef]

8. Hentrich, D.; Taabache, S.; Brezesinski, G.; Lange, N.; Unger, W.; Kübel, C.; Bertin, A.; Taubert, A. A Dendritic Amphiphile for Efficient Control of Biomimetic Calcium Phosphate Mineralization. Macromol. Biosci. 2017, 17, 1600524. [CrossRef] [PubMed]

9. Ignatova, M.; Voccia, S.; Gabriel, S.; Gilbert, B.; Cossement, D.; Jérôme, R.; Jérôme, C. Stainless steel grafting of hyperbranched polymer brushes with an antibacterial activity: Synthesis, characterization, and properties. Langmuir 2009, 25, 891-902. [CrossRef] [PubMed]

10. Letsche, S.A.; Steinbach, A.M.; Pluntke, M.; Marti, O.; Ignatius, A.; Volkmer, D. Usage of polymer brushes as substrates of bone cells. Front. Mater. Sci. China 2009, 3, 132-144. [CrossRef]

11. Liu, W.; Lipner, J.; Xie, J.; Manning, C.N.; Thomopoulos, S.; Xia, Y. Nanofiber Scaffolds with Gradients in Mineral Content for Spatial Control of Osteogenesis. ACS Appl. Mater. Interfaces 2014, 6, 2842-2849. [CrossRef] [PubMed]

12. Ramstedt, M.; Cheng, N.; Azzaroni, O.; Mossialos, D.; Mathieu, H.J.; Huck, W.T.S. Synthesis and characterization of poly(3-sulfopropylmethacrylate) brushes for potential antibacterial applications. Langmuir 2007, 23, 3314-3321. [CrossRef] [PubMed] 
13. Sin, M.C.; Sun, Y.M.; Chang, Y. Zwitterionic-Based Stainless Steel with Well-Defined Polysulfobetaine Brushes for General Bioadhesive Control. ACS Appl. Mater. Interfaces 2014, 6, 861-873. [CrossRef] [PubMed]

14. Steinbach, A.; Tautzenberger, A.; Ignatius, A.; Pluntke, M.; Marti, O.; Volkmer, D. Coatings from micropatterned sulfobetaine polymer brushes as substrates for MC3T3-E1 cells. J. Mater. Sci. Mater. Med. 2012, 23, 573-579. [CrossRef] [PubMed]

15. Mai, T.; Rakhmatullina, E.; Bleek, K.; Boye, S.; Yuan, J.; Völkel, A.; Gräwert, M.; Cheaib, Z.; Eick, S.; Günter, C.; et al. Poly(ethylene oxide)-b-poly(3-sulfopropyl methacrylate) Block Copolymers for Calcium Phosphate Mineralization and Biofilm Inhibition. Biomacromolecules 2014, 15, 3901-3914. [CrossRef] [PubMed]

16. Aizenberg, J.; Black, A.J.; Whitesides, G.M. Oriented Growth of Calcite Controlled by Self-Assembled Monolayers of Functionalized Alkanethiols Supported on Gold and Silver. J. Am. Chem. Soc. 1999, 121, 4500-4509. [CrossRef]

17. Armarego, W.L.F.; Chai, C. Purification of Laboratory Chemicals, 6th ed.; Elsevier Science: Amsterdam, The Netherlands, 2009; ISBN 978-1-85617-567-8.

18. Mai, T.; Boye, S.; Yuan, J.; Völkel, A.; Gräwert, M.; Günter, C.; Lederer, A.; Taubert, A. Poly(ethylene oxide)-based block copolymers with very high molecular weights for biomimetic calcium phosphate mineralization. RSC Adv. 2015, 5, 103494-103505. [CrossRef]

19. Nečas, D.; Klapetek, P. Gwyddion: An open-source software for SPM data analysis. Cent. Eur. J. Phys. 2012, 10, 181-188. [CrossRef]

20. Wiemann, M.; Bingmann, D.; Franzka, S.; Hartmann, N.; Urch, H.; Epple, M. Oriented Growth of Osteoblast-like Cells on Two- Dimensionally Structured Films of Functionalized Calcium Phosphate Nanoparticles on a Silicon Substrate. Adv. Eng. Mater. 2007, 9, 1077-1081. [CrossRef]

21. Wolski, K.; Szuwarzyński, M.; Zapotoczny, S. A facile route to electronically conductive polyelectrolyte brushes as platforms of molecular wires. Chem. Sci. 2015, 6, 1754-1760. [CrossRef] [PubMed]

22. Parry, K.L.; Shard, A.G.; Short, R.D.; White, R.G.; Whittle, J.D.; Wright, A. ARXPS characterisation of plasma polymerised surface chemical gradients. Surf. Interface Anal. 2006, 38, 1497-1504. [CrossRef]

23. Scofield, J.H. Hartree-Slater subshell photoionization cross-sections at 1254 and 1487 eV. J. Electron Spectros. Relat. Phenomena 1976, 8, 129-137. [CrossRef]

24. Tanuma, S.; Powell, C.J.; Penn, D.R. Calculations of electron inelastic mean free paths. V. Data for 14 organic compounds over the 50-2000 eV range. Surf. Interface Anal. 1994, 21, 165-176. [CrossRef]

25. Bretschneider, T.; Diez, S.; Anderson, K.; Heuser, J.; Clarke, M.; Müller-Taubenberger, A.; Köhler, J.; Gerisch, G. Dynamic Actin Patterns and Arp2/3 Assembly at the Substrate-Attached Surface of Motile Cells. Curr. Biol. 2004, 14, 1-10. [CrossRef] [PubMed]

26. Batsios, P.; Baumann, O.; Gräf, R.; Meyer, I. Isolation of Dictyostelium Nuclei for Light and Electron Microscopy. In Dictyostelium Discoideum Protocols; Eichinger, L., Rivero, F., Eds.; Humana Press: New York, NY, USA, 2013; pp. 283-294, ISBN 978-1-62703-302-2.

27. Karakassides, M.A. An Infrared Reflectance Study of Si-O Vibrations in Thermally Treated Alkali-Saturated Montmorillonites. Clay Miner. 1999, 34, 429-438. [CrossRef]

28. Luna-López, J.A.; Carrillo-López, J.; Aceves-Mijares, M.; Morales-Sánchez, A.; Falcony, C.; Luna-Lope, J.A.; Carrillo-Lopez, J.; Aceves-Mijares, M.; Morales-Sanchez, A.; Falcony, C. FTIR and photoluminescence of annealed silicon rich oxide films. Superf. Vacio 2009, 22, 11-14.

29. Thomas, S. Online Programme zur Spektroskopie. Available online: http://www.spec-online.de/ (accessed on 10 May 2018).

30. Koutsopoulos, S. Synthesis and characterization of hydroxyapatite crystals: A review study on the analytical methods. J. Biomed. Mater. Res. 2002, 62, 600-612. [CrossRef] [PubMed]

31. Ren, F.; Ding, Y.; Leng, Y. Infrared spectroscopic characterization of carbonated apatite: A combined experimental and computational study. J. Biomed. Mater. Res. Part A 2014, 102, 496-505. [CrossRef] [PubMed]

32. Rey, C.; Shimizu, M.; Collins, B.; Glimcher, M.J. Resolution-enhanced fourier transform infrared spectroscopy study of the environment of phosphate ions in the early deposits of a solid phase of calcium-phosphate in bone and enamel, and their evolution with age. I: Investigations in thev 4 PO4 domain. Calcif. Tissue Int. 1990, 46, 384-394. [CrossRef] [PubMed]

33. Boyd, I.W.; Wilson, J.I.B. A study of thin silicon dioxide films using infrared absorption techniques. J. Appl. Phys. 1982, 53, 4166-4172. [CrossRef] 
34. Mansour, N.; Momeni, A.; Karimzadeh, R.; Amini, M. Surface effects on the luminescence properties of colloidal silicon nanocrystals in water. Phys. Scr. 2013, 87, 035701. [CrossRef]

35. Pluchery, O.; Costantini, J.-M. Infrared spectroscopy characterization of 3C-SiC epitaxial layers on silicon. J. Phys. D Appl. Phys. 2012, 45, 495101. [CrossRef]

36. Bohner, M. Calcium orthophosphates in medicine: from ceramics to calcium phosphate cements. Injury 2000, 31 (Suppl. 4), 37-47. [CrossRef]

37. Schweizer, S.; Taubert, A. Polymer-controlled, bio-inspired calcium phosphate mineralization from aqueous solution. Macromol. Biosci. 2007, 7, 1085-1099. [CrossRef] [PubMed]

38. Wopenka, B.; Pasteris, J.D. A mineralogical perspective on the apatite in bone. Mater. Sci. Eng. C 2005, 25, 131-143. [CrossRef]

39. Goldmann, A.S.; Tischer, T.; Barner, L.; Bruns, M.; Barner-Kowollik, C. Mild and Modular Surface Modification of Cellulose via Hetero Diels-Alder (HDA) Cycloaddition. Biomacromolecules 2011, 12, 1137-1145. [CrossRef] [PubMed]

40. Zydziak, N.; Hübner, C.; Bruns, M.; Barner-Kowollik, C. One-Step Functionalization of Single-Walled Carbon Nanotubes (SWCNTs) with Cyclopentadienyl-Capped Macromolecules via Diels-Alder Chemistry. Macromolecules 2011, 44, 3374-3380. [CrossRef]

41. Chusuei, C.C.; Goodman, D.W.; van Stipdonk, M.J.; Justes, D.R.; Schweikert, E.A. Calcium Phosphate Phase Identification Using XPS and Time-of-Flight Cluster SIMS. Anal. Chem. 1999, 71, 149-153. [CrossRef] [PubMed]

42. Fleet, M.E.; Liu, X. Coupled substitution of type A and B carbonate in sodium-bearing apatite. Biomaterials 2007, 28, 916-926. [CrossRef] [PubMed]

43. Fleet, M.E.; Liu, X.; King, P.L. Accommodation of the carbonate ion in apatite: An FTIR and X-ray structure study of crystals synthesized at 2-4 GPa. Am. Mineral. 2004, 89, 1422-1432. [CrossRef]

44. Vignoles, M.; Bonel, G.; Holcomb, D.W.; Young, R.A. Influence of preparation conditions on the composition of type B carbonated hydroxyapatite and on the localization of the carbonate ions. Calcif. Tissue Int. 1988, 43, 33-40. [CrossRef] [PubMed]

45. Pelorgeas, S.; Martin, J.B.; Satre, M. Cytotoxicity of dichloromethane diphosphonate and of 1-hydroxyethane-1,1-diphosphonate in the amoebae of the slime mould Dictyostelium discoideum. A 31P NMR study. Biochem. Pharmacol. 1992, 44, 2157-2163. [CrossRef]

46. Pozzolini, M.; Sturla, L.; Cerrano, C.; Bavestrello, G.; Camardella, L.; Parodi, A.M.; Raheli, F.; Benatti, U.; Müller, W.E.G.; Giovine, M. Molecular cloning of silicatein gene from marine sponge Petrosia ficiformis (Porifera, Demospongiae) and development of primmorphs as a model for biosilicification studies. Mar. Biotechnol. (N. Y.) 2005, 6, 594-603. [CrossRef] [PubMed]

47. Shkilnyy, A.; Gräf, R.; Hiebl, B.; Neffe, A.T.; Friedrich, A.; Hartmann, J.; Taubert, A. Unprecedented, low cytotoxicity of spongelike calcium phosphate/poly(ethylene imine) hydrogel composites. Macromol. Biosci. 2009, 9, 179-186. [CrossRef] [PubMed]

48. Barbey, R.R.; Lavanant, L.; Paripovic, D.; Schüwer, N.; Sugnaux, C.; Tugulu, S.; Klok, H.-A.; Schuwer, N.; Sugnaux, C.; Tugulu, S.; et al. Polymer brushes via surface-initiated controlled radical polymerization: synthesis, characterization, properties, and applications. Chem. Rev. 2009, 109, 5437-5527. [CrossRef] [PubMed]

49. Brinks, M.K.; Studer, A. Polymer Brushes by Nitroxide-Mediated Polymerization. Macromol. Rapid Commun. 2009, 30, 1043-1057. [CrossRef] [PubMed]

50. Howarter, J.A.; Youngblood, J.P. Self-Cleaning and Anti-Fog Surfaces via Stimuli-Responsive Polymer Brushes. Adv. Mater. 2007, 19, 3838-3843. [CrossRef]

51. Kobayashi, M.; Terayama, Y.; Yamaguchi, H.; Terada, M.; Murakami, D.; Ishihara, K.; Takahara, A. Wettability and antifouling behavior on the surfaces of superhydrophilic polymer brushes. Langmuir 2012, 28, 7212-7222. [CrossRef] [PubMed]

52. Mittal, V. Polymer Brushes: Substrates, Technologies, and Properties; CRC Press: Boca Raton, FL, USA, 2012.

53. Zhou, F.; Huck, W.T.S. Surface grafted polymer brushes as ideal building blocks for "smart" surfaces. Phys. Chem. Chem. Phys. 2006, 8, 3815-3818. [CrossRef] [PubMed]

54. Minko, S. Grafting on Solid Surfaces: “Grafting to" and "Grafting from" Methods. In Polymer Surfaces and Interfaces; Springer: Berlin/Heidelberg, Germany, 2008; pp. 215-234. ISBN 9783540738640. 
55. Matyjaszewski, K. Atom Transfer Radical Polymerization (ATRP): Current status and future perspectives. Macromolecules 2012, 45, 4015-4039. [CrossRef]

56. Szwarc, M. 'Living' Polymers. Nature 1956, 178, 1168-1169. [CrossRef]

57. Szwarc, M. Living polymers. Their discovery, characterization, and properties. J. Polym. Sci. Part A Polym. Chem. 1998, 36, ix-xv. [CrossRef]

58. Dorozhkin, S.V. Amorphous Calcium Orthophosphates: Nature, Chemistry and Biomedical Applications. Int. J. Mater. Chem. 2012, 2, 19-46. [CrossRef]

59. Elyada, A.; Garti, N.; Füredi-Milhofer, H. Polyelectrolyte multilayer-calcium phosphate composite coatings for metal implants. Biomacromolecules 2014, 15, 3511-3521. [CrossRef] [PubMed]

60. LeGeros, R.Z. Properties of osteoconductive biomaterials: Calcium phosphates. Clin. Orthop. Relat. Res. 2002, 81-98. [CrossRef]

61. Eanes, E.D. Amorphous Calcium Phosphate. In Octacalcium Phosphate; KARGER: Basel, Switzerland, 2001; pp. 130-147.

62. Gibson, I.R.; Bonfield, W. Novel synthesis and characterization of an AB-type carbonate-substituted hydroxyapatite. J. Biomed. Mater. Res. 2002, 59, 697-708. [CrossRef] [PubMed]

63. Boonen, S.; Vanderschueren, D.; Callewaert, F.; Haentjens, P. Aging and Bone Loss. Osteoporos. Men 2010, 89, 207-219. [CrossRef]

64. Li, Z.; Pasteris, J.D. Tracing the pathway of compositional changes in bone mineral with age: Preliminary study of bioapatite aging in hypermineralized dolphin's bulla. Biochim. Biophys. Acta Gen. Subj. 2014, 1840, 2331-2339. [CrossRef] [PubMed]

65. Yerramshetty, J.S.; Lind, C.; Akkus, O. The compositional and physicochemical homogeneity of male femoral cortex increases after the sixth decade. Bone 2006, 39, 1236-1243. [CrossRef] [PubMed]

66. Rey, C.; Shimizu, M.; Collins, B.; Glimcher, M.J. Resolution-enhanced fourier transform infrared spectroscopy study of the environment of phosphate ion in the early deposits of a solid phase of calcium phosphate in bone and enamel and their evolution with age: 2. Investigations in the v3 PO4 domain. Calcif. Tissue Int. 1991, 49, 383-388. [CrossRef] [PubMed]

67. Legros, R.; Balmain, N.; Bonel, G. Age-related changes in mineral of rat and bovine cortical bone. Calcif. Tissue Int. 1987, 41, 137-144. [CrossRef] [PubMed]

68. Tugulu, S.; Harms, M.; Fricke, M.; Volkmer, D.; Klok, H.-A. Polymerbürsten als ionotrope Matrices für die gezielte Herstellung mikrostrukturierter dünner Calcit-Filme. Angew. Chem. 2006, 118, 7619-7623. [CrossRef]

69. Tugulu, S.; Barbey, R.; Harms, M.; Fricke, M.; Volkmer, D.; Rossi, A.; Klok, H.-A. Synthesis of Poly(methacrylic acid) Brushes via Surface-Initiated Atom Transfer Radical Polymerization of Sodium Methacrylate and Their Use as Substrates for the Mineralization of Calcium Carbonate. Macromolecules 2007, 40, 168-177. [CrossRef]

70. Van den Beucken, J.J.J.P.; Walboomers, X.F.; Leeuwenburgh, S.; Vos, M.F.J.; Sommerdijk, N.A.J.M.; Nolte, R.J.M.; Jansen, J.A. DNA-Coatings: Bioactive Properties and Effects on Osteoblast-Like Cells. Key Eng. Mater. 2008, 361-363, 605-608. [CrossRef]

(c) 2018 by the authors. Licensee MDPI, Basel, Switzerland. This article is an open access article distributed under the terms and conditions of the Creative Commons Attribution (CC BY) license (http://creativecommons.org/licenses/by/4.0/). 